\title{
Optimization of Bike Routes for Sustainable Urban Road Network
}

\section{Marwa S. El-Bany}

Lecturer, Transportation Planning and Traffic Engineering, Faculty of Engineering, Port Said University, EGYPT

Corresponding Contact:

Email: $\underline{\text { mr2.elbany@gmail.com }}$

Manuscript Received: 30 Dec 2019

Accepted: 20 June 2021

\begin{abstract}
The transport department of urban cities always needs to keep abreast of sustainable developments such as in Port Said city that is an important urban city in Egypt. Bike routes planning mission is not an easy occupation, especially in developing countries. Mixed traffic is the main shape of the transportation system in most of their systems. The increase of the bike user's percent is an expected objective and be one of the modern sustainable transport solutions. On another side, a lot of problems and accidents had been occurred according to bike crossings among other transport vehicles; cars, buses, taxis, and others. This paper aims at studying the introduction of the bike route's effectiveness. It concludes the driver's reaction to a definite planning scenario and the optimistic effect of the modal change on the objective function that has been assumed by attaching a suitable time-saving for bike users using the Artificial Neural Network ANNs Approach. It shows the effect of bike speed change on the route using a greedy algorithm. The study designated only four streets from seven selected streets to be suitable routes for bike routes introduction. The average bike speed is predicted to increase from $1.5 \mathrm{~km}$ per hour to be $2.4 \mathrm{~km}$ per hour after introducing the bike routes.
\end{abstract}

Keywords: bike routes, neural network, bike welfare, sustainable transport systems

This article is is licensed under a Creative Commons Attribution-NonCommercial 4.0 International License.

Attribution-NonCommercial (CC BY-NC) license lets others remix, tweak, and build upon work non-commercially, and although the new works must also acknowledge \& be non-commercial.

\section{INTRODUCTION}

Nowadays, the bike routes are transport technique that decisions makers tends to use. Many quantitative and qualitative road attributes have to take into account for new policy or introduction of any idea. The bike routes have the following advantages:

- $\quad$ Sustainable, comfort and safety improvements. It causes reduction in accelerations and decelerations when the driver stops and go in case of crossing between cars

- A decrease in waiting and travel time

- Simple and small form. The only moving parts on a single speed bicycle are the brakes, wheels, and cranks, which makes changes over time minimal.

- $\quad$ Low maintenance cost and small parking space. 
The bike is a safe transport mode in case of moving in private lanes but when moving among other vehicles, it becomes dangerous mode and loss this advantage. So, the needs of bike routes are important solutions especially in developing countries with nonexpected behavior of other mode's users.

\section{The mobility of Port Said's transport system}

Port Said city has General Urban Transport Plan that expected the internal movements at 540000 travellers per day; the $86 \%$ of such demand uses the private car, whereas others choose the public transport such as mini-bus, which considers a critical situation for the transport sector in 2019 (PSGTMAP, 2019). Furthermore, the average travel speed on its inner-city road network can't be over $42 \mathrm{~km} / \mathrm{h}$ that indicates low mobility. Other alarming data is the number of bikes accidents per annum within the inner-city area of Port Said that is about 227 accidents per year inside the city (PSTA, 2019). In order to opposite this situation, transport administrators have recently launched Sustainable Plan of Transport for the next ten years (Elgioshy, 2017), for a extra effective public transport system, which suggests the bike development and give the opportunity to sustainable transport.

\section{Route Planning in Port Said Road Network}

The multimodal route planning problem, which seeks journeys joining schedule-based transportation (buses, cars) with un restricted modes (walking, driving), is even safer, relying on approximate solutions even for the problem inputs. So, the optimum set of routes has been determined through iterations of a greedy algorithm ( $\mathrm{Li}, 2017)$. It is an application of mathematical techniques to optimization research. In this study, the main objective is to minimize the total user waiting time (Zheng et al., 2009).

\section{BiKe Routes Model}

This study proposes the input for the bike routes model recording the different transport policy actions for the numerous combinations of the aforementioned criteria. Bike frequency and the width of the road are manual collected and from Google Map (Port Said, Egypt). The policy actions were recognized according to the collected data in working days. Data was collected manually for the seven main streets that considered the main arterial streets around the city; Mohamed Ali st.(Al-shohada), 23 Jul st., 23 Dec st., el-30th st., el-nasr st., Tarh el-bahr st., and el-Gomhoria st. Each street was classified into homogenous segment with different length as shown in Fig.1. In table1, there are five actions according to policy criteria; have to make bike route, closed to traffic zone, the bike lane have to be weighed, and no action.

Table 1: Considering actions of policy

\begin{tabular}{|c|c|c|}
\hline \multicolumn{2}{|c|}{ Criteria } & Policy action \\
\hline $\begin{array}{c}\text { Bike frequency, } \\
\boldsymbol{b}_{f} \text { (bike/hr) }\end{array}$ & $\begin{array}{c}\text { Road width at section of the proposed bike } \\
\text { routes (excluding parking length), } \mathbf{L}(\mathbf{m})\end{array}$ & \\
\hline$F_{b} \geq 40$ & $\mathrm{~L}>6$ & Have to make bike lane \\
\hline$F_{b} \geq 40$ & $\mathrm{~L}<6$ & Prohibited traffic zone \\
\hline $15 \leq F_{b}<40$ & $\mathrm{~L}>6$ & $\begin{array}{c}\text { The bike lane solution have } \\
\text { to be evaluated }\end{array}$ \\
\hline $15 \leq F_{b}<40$ & $\mathrm{~L}<6$ & No action \\
\hline$F_{b}<15$ & -any width & No action \\
\hline
\end{tabular}




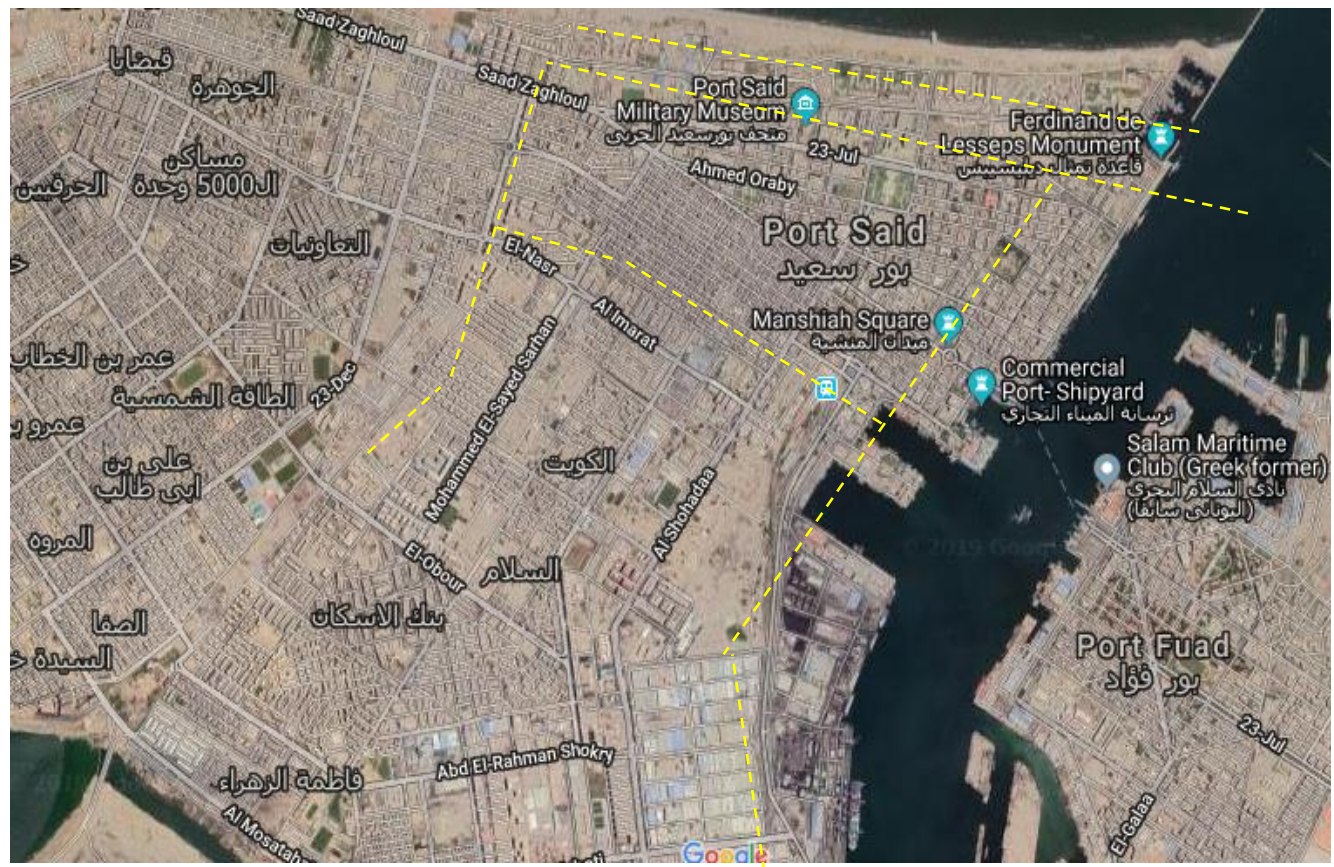

Figure 1: Port Said Google Map with selected streets (Port Said, Egypt).

\section{MODEL FrameWORK}

The study commotion presented a quantitative methodology for planning the introduction of bike routes into the Port Said urban road network. The resulting methodology has been applied: the present lane systems have been compared with the model-based. In actual, to recognize the study area within Port Said and to select the roads for its design model, concerning the private investment level of service, the study considered parameters such as bike frequency, number of lines, and the road width as a geometric parameter. The trade-off function (T.O.) between the welfares of bike transport users and other significant modes such as car and bus is a multi-components function representing with the following equation:

T.O. $=f\left(d C_{c a r}, d T_{C a r}, d C_{B u s}, d C_{B u s,} d T_{\text {bike }}\right)$

Where:

$d C_{c a r}:$ monetary cost risen for car users

$d T_{c a r}:$ the rise in travel time for car users

$d C_{b u s}$ : the rise in monetary cost for bus users

$d T_{b u s}:$ the rise in travel for bus users

$d T_{\text {bike: }}$ the reduction in travel time for bike users

Logically, the behavior of other modes transport users is expected to change when there are bike lanes in the street. The effect of introduce any proposed routes on its travel speed has been assessed using a neural network (Çetiner et al., 2010). 
The optimal bike lane system for Port Said has been investigated adopting the multi-agent objective function considering buses and cars movement (the major presence on roads) as these have the maximum effect on bike speed neglecting other types of vehicle. That function has five components for each transport mode. These components are computed by using the following equations:

$$
\begin{aligned}
& d C_{c a r}=C_{c} \cdot d C_{C b} \\
& d T_{c a r}=T_{c} \cdot d T_{c b} \\
& d C_{b u s}=C_{B} \cdot d C_{B b} \\
& d T_{b u s}=T_{B} \cdot d T_{B b} \\
& d T_{b i k e}=T_{b} \cdot d T_{b b}
\end{aligned}
$$

As $C_{C}$ and $C_{B}$ is the cost of using car and bus per km; prospectively, $d C_{C b}$ and $d C_{B b}$ are the variation of $C_{C}$ and $C_{B}$ variables when applying bike lanes; $T_{C}$ and $T_{B}$ are the time per

\begin{tabular}{|c|c|c|c|c|}
\hline Road name & Segments & $\begin{array}{c}\text { Length } \\
\mathrm{km}\end{array}$ & $\begin{array}{l}\text { Average bike speed } \\
\text { (present case) } \mathrm{km} / \mathrm{hr}\end{array}$ & $\begin{array}{l}\text { Average bike speed } \\
\text { (after routes) } \mathrm{km} / \mathrm{hr}\end{array}$ \\
\hline \multirow[t]{4}{*}{ al-shohadaa } & 1 & 0.6 & 1.5 & 2.8 \\
\hline & 2 & 0.3 & 1.6 & 2.5 \\
\hline & 3 & 1.2 & 1.2 & 2.1 \\
\hline & 4 & 0.4 & 1.9 & 2.7 \\
\hline \multirow[t]{4}{*}{23 July st. } & 1 & 0.6 & 2.0 & 2.6 \\
\hline & 2 & 0.5 & 2.1 & 2.6 \\
\hline & 3 & 0.6 & 1.1 & 1.9 \\
\hline & 4 & 0.8 & 1.0 & 2.2 \\
\hline \multirow[t]{5}{*}{23 December st. } & 1 & 0.6 & 1.3 & 2.4 \\
\hline & 2 & 0.6 & 1.3 & 2.8 \\
\hline & 3 & 0.4 & 1.2 & 2.3 \\
\hline & 4 & 0.7 & 1.5 & 2.1 \\
\hline & 5 & 0.4 & 1.2 & 2.3 \\
\hline \multirow[t]{2}{*}{ el-30th st., ${ }^{*}$} & 1 & 0.5 & 0.9 & 2.5 \\
\hline & 2 & 0.7 & 1.1 & 2.4 \\
\hline \multirow[t]{2}{*}{ el-nasr st. } & 1 & 0.4 & 2.1 & 2.4 \\
\hline & 2 & 0.3 & 1.1 & 2.3 \\
\hline \multirow[t]{4}{*}{ Tarh el-bahr st. } & 1 & 0.4 & 1.0 & 2.1 \\
\hline & 2 & 0.6 & 1.4 & 1.8 \\
\hline & 3 & 0.8 & 1.6 & 2.5 \\
\hline & 4 & 0.2 & 1.2 & 1.9 \\
\hline \multirow[t]{2}{*}{ el-Gomhoria st. } & 1 & 0.6 & 1.8 & 1.9 \\
\hline & 2 & 0.5 & 2.0 & 2.5 \\
\hline
\end{tabular}
kilometer for cars and buses; $d T_{c b}$ and $d T_{B b}$ are the variation of time when applying bike lanes; and $d T_{b b}$ is the variation of $T_{b}$ variable arising from a present route case that measures the travel time spent by bike.

Table 2: ANNs output of the expected bike speed variation

* This road has mini-buses with many stops and high traffic so it is out of model 
Data was collected manually for the chosen main streets. Each street was classified into homogenous segment with different length. Now, lengths are known, travel times by bikes are collected for recent case, and the expected travel times are predicted by making a questionnaire for about 300 bike riders as a sample using the selected routes.

The values of $d C_{C b}, d T_{c b}, d C_{B b}, \mathrm{~d} T_{B b}$ were calculated by making an origin - destination matrix for the private transport demand of Port Said city during the peak period of a working day except the value of time for bike $\left(d T_{b b}\right)$ variable. For determination such variable, the neural network-based methodology and greedy algorithm had been used. The outputs of the expected average bike speed after bike routes implementation are illustrated in the above table 2.

From the table, it can be noticed that the bike speed is increased for all segment of road but this is not an indication of the mobility without making the greedy algorithm.

\section{Artificial Neural Network-based ANNs methodology and greedy algorithm}

The Artificial Neural Network-Based ANNs methodology is used successfully for solving many problems in numerous field of science by means of the available data (Zhang et al., 2018; Cook et al., 2016). Prediction of speed in Port Said city has been a great concern of this study. The determination of the variation of $T_{b}$-hour variable arising from a present route case, two elements want to be evaluated; the bike transport travel speed for links under analysis (namely, the appropriate locations for bike ways) and the number of the bike transport users. This methodology has used a neural network which has multi-layer perceptron architecture (Çetiner et al., 2010). For more details, the neural network-based methodology structure has been illustrated in Fig. 2.

It contains three layers reflect the processes of collecting data and functions; input layer, processing layer, and output layer. The input layer has a number of neurons equal to the one of the variables detected for a generic route section. It uses to transfer input data into a processing layer through linear mathematical functions. To transfer data, the processing layer is a tool needed for this function. Output layer holds a neuron for estimating the speed of bike before and after implementation of the proposed routes. All data is calculated by a binary stated preference tool (La Franca et al., 2004).

There are many of quantitative and qualitative road attributes represents needed for processes empirical data which have responds of (Yes/No) such as bike lanes availability, number of pedestrian crossings, parking possibility within the bike lane, misbehavior of the parking, and presence of side shops (La Franca et al., 2004). Some questions are about delay, trip length, travel time, average speed. It looks like a questionnaire.

According to these variables; the analyzed inter-city roads have been subdivided into multi-homogeneous segments. Furthermore, the above-mentioned empirical road data have been normalized to be handled by the neural network as dimensionless and comparable inputs. for calculating the number of bike users, manual survey had been implemented during the peak hour of a working day (April , 2019) has been assigned to the corresponding graph using the hyper-path minimum algorithm, with the expected rising of the bike travel speed due to the proposed bike routes. 


\section{ANALYSIS AND RESULTS}

From the collected data, some roads were selected to be suitable for reaching the urgent facilities for example; schools, faculties, government interests, and shopping activities. In this paper, the prediction model that has been developed and used in any period of time then the approach converts the date-time information to a date-time format independent. The data of bike speed has two situations; the first is the present case in which the bikes move among all kind of traffic, the second is the bike has separately routes that can be estimated as the free speed as the street has minimum traffic flow at non-peak hours. Note that the bike speed is obviously vary based on the conditions in which the user riding such as the condition of pavement and traffic condition.

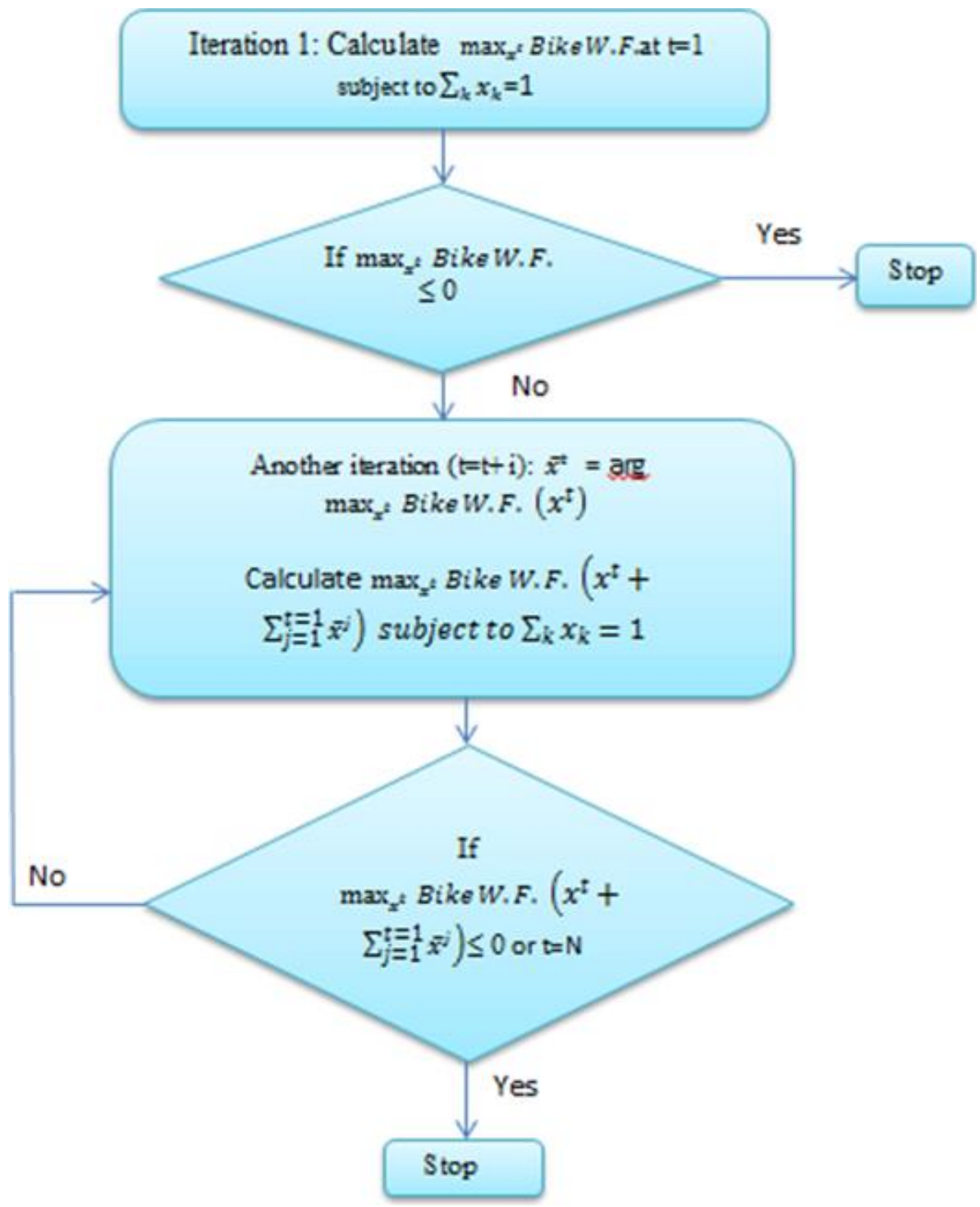

Figure 2: welfare greedy algorithm for the proposed policy 


\section{Where:}

$x$ : the location pattern vector of bike routes

$x_{k}$ : the generic element of $x$ according to those roads with a precarious bike frequency

(from 15 to 40). It equal to1 if the road $\mathrm{k}$ has already space for bike routes and 0 otherwise

After applying the previous algorithm (see Fig.2), the output helps to choose the suitable route. The outputs are illustrated in the following table.

The experiential method constructs the solution for bike routes problem through an optimization process. After calculating the bike speed for all roads, the value of time is estimated to describe the mobility of Port Said new system. To check the mobility of bike, the bike welfare will be estimated by the following proposed welfare objective function:

Bike w.F. $=a\left(d T_{b b}-d T_{c b}-d T_{B b}\right)-\left(b_{c} d C_{C b}-b_{B} d C_{B b}\right)$

As Bike w.F. is a welfare function for bike route policy, $a$ is the value of time (25 1.e /hour) (PSTA, 2019) that is multiplied by 1.3 to take into account the positive environmental impact of any transport service and to turn from time to cost. $b_{C}$ and $b_{B}$ are the transport costs (10 and 2 L.E per $\mathrm{km}$ for car and bus; respectively). The cost of using bike is equal to zero.

For the determination of $d C_{c}$ and $d T_{c}$, the O-D matrix representing the cars transport demand of Port Said city throughout the peak period of a working day (April-2019) has been assigned taking into account the expected reduction in space for car and bus movements, due to the implementation of bike routes. The next outcomes was achieved by the greedy algorithm (Zheng et al., 2009) applied to determine the optimal set of bike routes for Port Said city transport system.

The greedy algorithm is used for calculating the user's maximization welfare function when using bike routes. The policy action into road $k$ is estimated after making iterations. If the iteration stops that means that the selected road is suitable for the policy; if not that means that it is not suitable (see Table 1of bike frequency).

Table 3: The chosen bike routes location using the greedy algorithm

\begin{tabular}{|c|c|c|c|c|c|}
\hline & \multicolumn{5}{|c|}{ The cost of impact $(L . E)$ on the welfare function with policy } \\
\hline $\begin{array}{c}\text { No.of greedy } \\
\text { steps }\end{array}$ & $\begin{array}{c}\text { al-shohadaa } \\
\text { st. }\end{array}$ & $\begin{array}{c}\mathbf{2 3} \text { July } \\
\text { st. }\end{array}$ & $\begin{array}{c}\mathbf{2 3} \text { December } \\
\text { st. }\end{array}$ & $\begin{array}{c}\text { el-nasr } \\
\text { st. }\end{array}$ & $\begin{array}{c}\text { Tarh el- } \\
\text { bahr st. }\end{array}$ \\
\hline $\mathbf{1}^{\text {st }}$ & +25.39 & +73.25 & +23.16 & -4.06 & +104.03 \\
\hline $\mathbf{2}^{\text {nd }}$ & +36.09 & +80.34 & +44.08 & +16.93 & - \\
\hline $\mathbf{3}^{\text {rd }}$ & +51.78 & +94.78 & - & +11.03 & - \\
\hline $\mathbf{4}^{\text {th }}$ & - & - & - & -6.23 & - \\
\hline $\mathbf{5}^{\text {th }}$ & - & - & - & -10.45 & - \\
\hline
\end{tabular}

The values of the welfare function show the impact of the policy on the bike welfare function. It can be notices that el-Nasr St. has a negative value for all iterations that means it cannot be suitable road for bikes. The optimal solution at every step is written in red font color. The final number refers to that the bike route can be implemented in the selected road at the previous iteration. So, Al-Shohada, 23 July, 23 December, and Tarh elBahr streets are selected to be the bike route policy in the new developing plan. 
Table 4: the model output of selected routes

\begin{tabular}{|c|c|c|}
\hline Road name & Segment & The model output \\
\hline \multirow[t]{4}{*}{ al-shohadaa } & 1 & $*$ \\
\hline & 2 & $*$ \\
\hline & 3 & $*$ \\
\hline & 4 & $*$ \\
\hline \multirow[t]{4}{*}{23 July st. } & 1 & * \\
\hline & 2 & $*$ \\
\hline & $3^{5}$ & * \\
\hline & $4^{5}$ & $*$ \\
\hline \multirow[t]{4}{*}{23 December st. } & 1 & * \\
\hline & 2 & * \\
\hline & 3 & * \\
\hline & 4 & $*$ \\
\hline \multirow[t]{2}{*}{ el-30th st. ${ }^{\mathrm{a}}$} & $1^{5}$ & - \\
\hline & $2^{5}$ & - \\
\hline \multirow[t]{2}{*}{ el-nasr st. } & $1^{5}$ & - \\
\hline & $2^{5}$ & $*$ \\
\hline \multirow[t]{4}{*}{ Tarh el-bahr st. } & 1 & $*$ \\
\hline & 2 & $*$ \\
\hline & 3 & * \\
\hline & 4 & - \\
\hline
\end{tabular}

*: means that the road is selected as a bike route

- : means that the road is not suitable to be a bike route

$\mathrm{s}$ : this road has mini-buses with many stops and high traffic so it is out of model

\section{Conclusions}

Nowadays, the decision makers of the transport sector in developing countries go towards increasing of sustainable transport modes such as bikes. They tried to reduce the car ownership and air pollutions. The actual bike transport is characterized by an average demand frequency of 40 passengers per hour and an average travel speed of $1.5 \mathrm{~km} / \mathrm{h}$. The study predicted that the bike speed will be $2.4 \mathrm{~km} / \mathrm{h}$ to give more bike mobility in roads. Also, it effects on reducing traffic jam and mobility through the main roads. So, the bike routes seem to be a fitting tool to improve the public transport performance at Port Said city; on the contrary, under a general point of view about the urban mobility system, the illustrated planning model excludes bike routes for some roads because of many considerations such as mini-buses stops and road width. It is considered a solution for traffic problems and one of the latest sustainable transport systems.

For describing the cost function of using each of bike or other modes, multi-agent objective function considering buses and cars movement had been formulated and is solved using the artificial neural network-based methodology. The greedy algorithm was used after calculating the user's maximization welfare function to identify the suitable bike routes. It demonstrated that Al-Shohada, 23 July, 23 December, and Tarh el-Bahr streets are suitable links to the bike route policy. This study is useful in taking a precise decision of 
introducing a green transport mode such as bike. The increasing of the bike user's percent is one of the recent sustainable transport solutions. Such qualitative planning approach needs to be extremely attractive for decision makers. The described methodology is an achievement technique but with lack of simulation graphs results.

\section{References}

Çetiner, B. G., Sari, M., Borat, O. (2010). A Neural Network Based Traffic-Flow Prediction Model. Mathematical and Computational Applications, 15(2), 269-278. https://doi.org/10.3390/mca15020269

Cook, J., Kimuyu, P., Blum, A. G., and Gatua, J. (2016). A Simple Stated Preference Tool for Estimating the Value of Travel Time in Rural Africa. Journal of Benefit-Cost Analysis, 7(2), 221 - 247. https://doi.org/10.1017/bca.2016.13

Elgioshy, S. M. M. (2017). Integration of Egypt's Transportation Plans 2030 with the New Silk Road Project. The International Schiller Institute - Presentation, November 2017. https://schillerinstitute.com/media/integration-egypts-transportation-plans-2030new-silk-road-project/

La Franca, L., Migliore, M., and Salvo, G. (2004). The automatic vehicle monitoring to improve the urban public transport management. AMAT, Palermo, ITALIA. https://www.academia.edu/17923448

Li, X. (2017). Solving transportation problems with warehouse locations based on greedy algorithm. International Conference on Advances in Materials, Machinery, Electrical Engineering, AMMEE 2017. https://doi.org/10.2991/ammee-17.2017.133

Port Said, Egypt. Google map website: https://shorturl.at/pLZ03

PSGTMAP. (2019). Port Said Government Transport Management Administration Plan.

PSTA. (2019). Port Said Traffic Administration, Statistics 2019.

Zhang, H., Wu, H., Sun, W., and Zheng, B. (2018). DEEP TRAVEL: a Neural Network Based Travel Time Estimation Model with Auxiliary Supervision. Proceedings of the Twenty-Seventh International Joint Conference on Artificial Intelligence (IJCAI-18), 3655-3661. https://www.ijcai.org/proceedings/2018/0508.pdf

Zheng, Y., Xu, C. \& Xue, J. (2009). A simple greedy algorithm for a class of shuttle transportation problems. Optimization Letters, 3, 491-497. https://doi.org/10.1007/s11590-009-0126-9

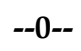


Article URL

https://i-proclaim.my/journals/index.php/abcjar/article/view/571 